\title{
Corrosion Control of Aluminium Alloy in Alkaline Solution Using Some Leave Extracts
}

\author{
Lebe A. Nnanna ${ }^{1, *}$, Ikechi U. Anozie ${ }^{1}$, Chigozie S. Akoma ${ }^{1}$, Ihebrodike M. Mejeha ${ }^{2}$, \\ Kelechukwu B. Okeoma ${ }^{2}$, Kingsley I. Mejeh $^{3}$ \\ ${ }^{1}$ Department of Physics/ Electronics, Abia State Polytechnic, Aba, P.M.B. 7166, Nigeria \\ ${ }^{2}$ Department of Physics, Federal University of Technology, Owerri, P.M.B. 1526, Nigeria \\ ${ }^{3}$ Department of Mechanical Engineering, Abia State Polytechnic, Aba, P. M. B. 7166, Nigeria
}

\begin{abstract}
The effect of Euphorbia hirta and Dialum guineense leave extracts on the corrosion of aluminium in $0.25 \mathrm{M}$ $\mathrm{NaOH}$ was investigated using gravimetric technique. It was shown that the presence of Euphorbia hirta and Dialum guineense leave extracts inhibited the corrosion of aluminium in the test solutions and that the inhibition efficiency depended on the concentration of the plant extract as well as on the time of exposure of the aluminium samples in $0.25 \mathrm{M} \mathrm{NaOH}$ solutions containing the extracts. Dialum guineense extract shows the best inhibition capability for aluminium corrosion in sodium hydroxide, probably, this is due to the planer orientation of the adsorbed extract molecules. Inhibition efficiency of the inhibitors tested increases with decreasing sodium hydroxide concentrations. The experimental data complied to both Langmuir and Temkin adsorption isotherms and the value and sign of the apparent activation energy of adsorption obtained suggests that inhibitor molecules have mixed inhibition mechanism.
\end{abstract}

Keywords Corrosion, Sodium Hydroxide, Inhibitors, Aluminium, Weight Loss

\section{Introduction}

Due to the lightweight and mechanical strength, aluminium and its alloys are very attractive materials for engineering applications. The interest of these materials arises from their importance in the recent civilization. Inhibition of metal corrosion by organic compounds is a result of adsorption of organic molecules or ions at the metal surface forming a protective layer. This layer reduces or prevents the corrosion of the metal. The extent of adsorption depends on the nature of the metal, the metal surface condition, the mode of adsorption, the chemical structure of the inhibitor, and the type of corrosive media[1]. Heteroatoms in the structure of inhibitor molecules, such as oxygen $(\mathrm{O})$, nitrogen $(\mathrm{N})$, phosphorous $(\mathrm{P})$,sulphur( $\mathrm{S})$ and the presence of aromatic rings or triple bonds enhance the adsorption process. It has been reported that the inhibition efficiency increases in the order: $\mathrm{O}<\mathrm{N}<\mathrm{S}<\mathrm{P}[2-6]$. Corrosion inhibition of aluminium and its alloys was the subject of numerous studies[7-11].The exploration of natural products of plant origin as inexpensive, eco-friendly corrosion inhibitors is an essential field of study. In addition to being environmentally friendly and ecologically acceptable, plant products are low cost, readily

* Corresponding author:

lebennanna@yahoo.com (Lebe A. Nnanna)

Published online at http://journal.sapub.org/materials

Copyright (C) 2011 Scientific \& Academic Publishing. All Rights Reserved available and renewable sources of materials. The extracts from their leaves, barks, seeds, fruits and roots comprise of mixtures of organic compounds and some have been reported to function as effective inhibitors of metal corrosion inhibition efficiencies using the plant extracts of Occimum viridis[12], Telferia occidentalis[13], Azadirachta indica[14], and Hibiscus sabdariffa[15]. The corrosion inhibition efficacy of these extracts is normally ascribed to the presence, in their composition, of complex organic species such as tannins, alkaloids, essential oils, flavonoids and nitrogen bases. The inhibiting effect of Euphorbia hirta and Dialum guineense plant extracts on aluminium alloy (AA3003) in $0.25 \mathrm{M} \mathrm{NaOH}$ was investigated. This study has dual purposes, first to establish the effectiveness of the plant extracts as corrosion inhibitors and secondly to attempt deduction of the inhibition mechanisms through adsorption isotherms. Mass loss can be determined gravimetrically, volumetrically and radiometrically, all are the direct measures of corrosion of these, gravimetric or mass loss are most used for inhibitor testing.

\section{Materials and Methods}

Aluminium alloy specimens having weight percentage composition as follows; $\mathrm{Si}-0.362 \%, \mathrm{Fe}-0.54 \%, \mathrm{Cu}-0.077 \%$, $\mathrm{Mn}-1.219 \%$, Ti- $0.026 \%$, Pb- $0.063 \%, \mathrm{Zn}-0.004 \%$ and the remainder being $\mathrm{Al}$ were used.

The inhibition efficiency of aluminium in aqueous solutions of sodium hydroxide $(\mathrm{NaOH})$ by using Euphorbia hirta 
and Dialum guineense plant extracts as inhibitors was determined by the gravimetric technique. The specimens were of dimension $2 \mathrm{~cm} \times 2 \mathrm{~cm}$ and thickness $1.32 \mathrm{~mm}$. The aluminium alloy specimen were polished mechanically using Sic emery papers of grade nos 220,400 , and 600 , washed thoroughly with distilled water and degreased with ethanol and acetone, air dried before being immersed in the alkaline solution. The blank corrodent was $0.25 \mathrm{M} \mathrm{NaOH}$ solution. Stock solutions of the plant extract were prepared by boiling weighed amounts of the dried and ground plant material for 3 hours in the $0.25 \mathrm{M} \mathrm{NaOH}$. The solutions were cooled and then filtered and stored. From the respective stock solutions, inhibitor test solutions were prepared in the concentration range of $0.1 \mathrm{~g} / \mathrm{L}$ to $0.3 \mathrm{~g} / \mathrm{L}$ using excess alkaline as solvent. The cleaned and dried specimens were weighed before in the respective test solution using electronic balance of series JA $1003 \mathrm{~A}$ with the accuracy of \pm 0.005 . Total immersion period was 4 hours. Tests were conducted with different concentrations of inhibitor. At the end of the tests, the specimens were carefully washed in absolute ethanol having used nitric acid to quench further corrosion from taking place, and then reweighed. Triplicate experiments were performed in each case and the mean values reported.

\section{Results and Discussion}

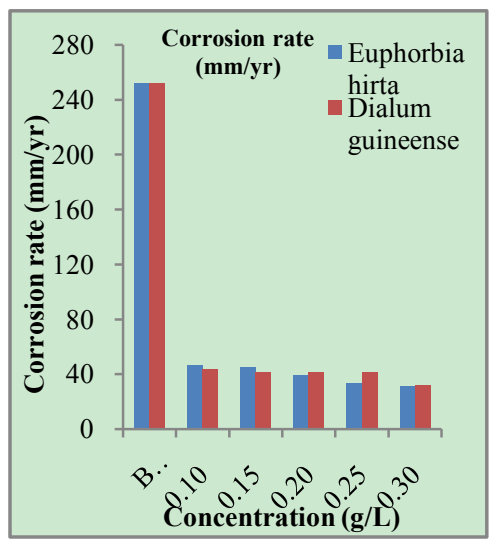

Figure 1. Corrosion rates of various concentrations of Euphorbia hirta and Dialum guineense extracts on aluminium alloy AA3003

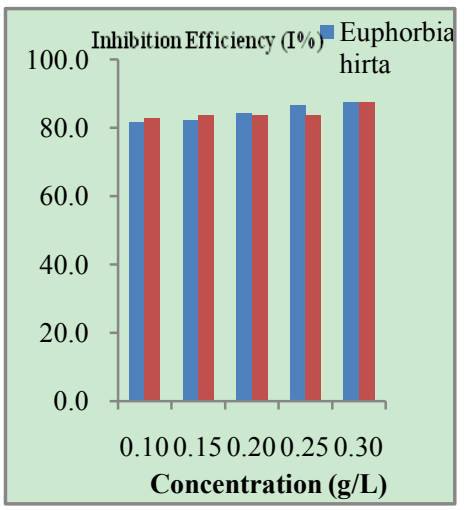

Figure 2. Inhibition efficiencies of various concentrations of Euphorbia hirta and Dialum guineense extracts on aluminium alloy AA3003

\subsection{The Langmuir Isotherm for AA3003 Aluminium Alloy}

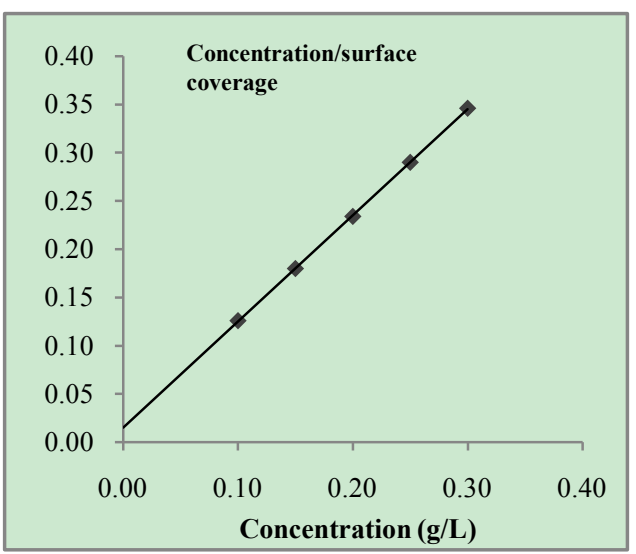

Figure 3. Langmuir isotherm for Euphorbia hirta adsorption on AA3003 aluminium alloy in $0.25 \mathrm{M} \mathrm{NaOH}$

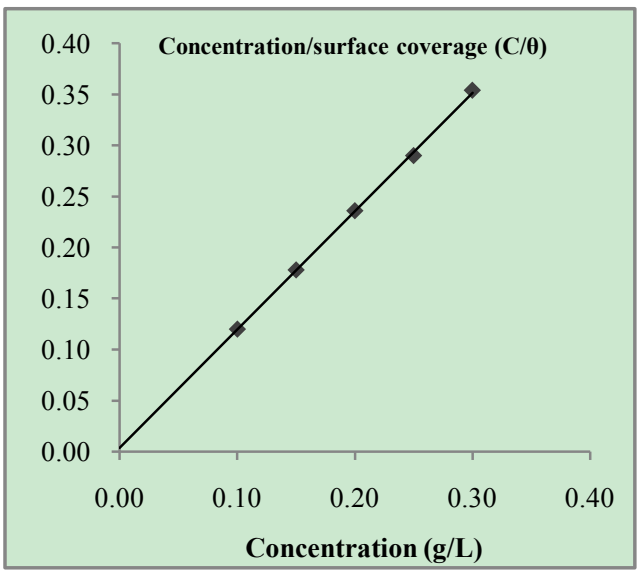

Figure 4. Langmuir isotherm for Dialum guineense adsorption on AA3003 aluminium alloy in $0.25 \mathrm{M} \mathrm{NaOH}$

Table 1. Values of Langmuir parameters for AA3003 aluminium alloy

\begin{tabular}{|c|c|c|c|c|c|}
\hline Plant Extract & Intercept & Slope & $\mathrm{K}$ & $\mathrm{R}^{2}$ & $\begin{array}{c}\Delta \mathrm{G}^{\circ} \\
(\mathrm{kJmol}-1)\end{array}$ \\
\hline $\mathrm{EH}$ in $\mathrm{NaOH}$ & 0.0152 & 1.10 & 65.79 & 0.9999 & -20.45 \\
\hline $\mathrm{DG}$ in $\mathrm{NaOH}$ & 0.0036 & 1.11 & 277.78 & 0.9994 & -24.04 \\
\hline
\end{tabular}

\subsection{The Temkin Isotherm for AA3003 Aluminium Alloy}

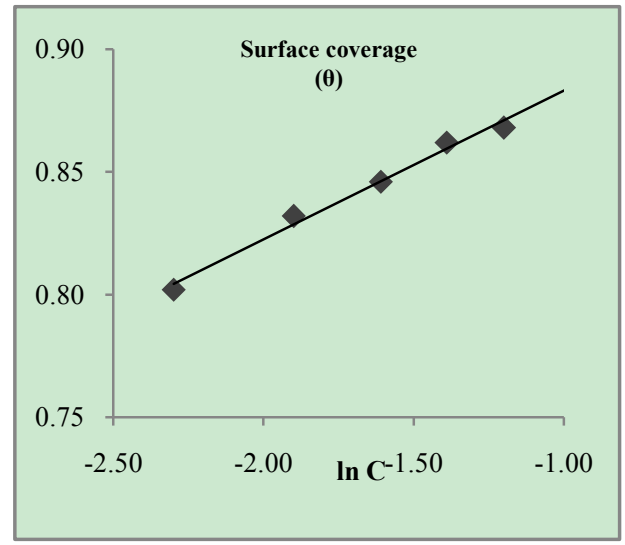

Figure 5. Temkin isotherm for Euphorbia hirta adsorption on AA3003 aluminium alloy in $0.25 \mathrm{M} \mathrm{NaOH}$ 


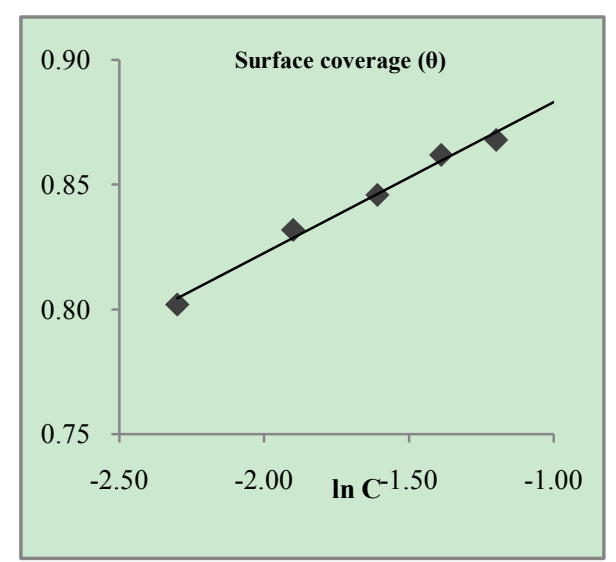

Figure 6. Temkin isotherm for Dialum guineense adsorption on AA3003 aluminium alloy in $0.25 \mathrm{M} \mathrm{NaOH}$

Table 2. Values of Temkin parameters for AA3003 aluminium alloy

\begin{tabular}{|c|c|c|c|c|c|}
\hline Plant Extract & Intercept & Slope & $\begin{array}{c}\mathrm{K} \\
(\mathrm{x} 106)\end{array}$ & $\mathrm{R} 2$ & $\begin{array}{c}\Delta \mathrm{G}^{\circ} \\
(\mathrm{kJmol}-1)\end{array}$ \\
\hline $\mathrm{EH}$ in $\mathrm{NaOH}$ & 0.94 & 0.06 & 5.84 & 0.9883 & -48.86 \\
\hline $\mathrm{DG}$ in $\mathrm{NaOH}$ & 0.88 & 0.02 & - & 0.8561 & -138.34 \\
\hline
\end{tabular}

Table 3. Calculated values of inhibition efficiency (I\%), apparent activation energy $\left(\mathrm{E}_{\mathrm{a}}\right)$ and heat of adsorption $\left(\mathrm{Q}_{\mathrm{ads}}\right)$ of Euphorbia hirta extract on AA3003 aluminium alloy in $0.25 \mathrm{M} \mathrm{NaOH}$ at different temperatures

\begin{tabular}{|c|c|c|c|c|}
\hline \multirow{2}{*}{$\begin{array}{c}\text { Extract Concen- } \\
\text { tration }\end{array}$} & \multicolumn{2}{|c|}{$\begin{array}{c}\text { Inhibition Efficiency } \\
\left(\mathrm{I}^{\circ}\right)\end{array}$} & \multirow{2}{*}{$\begin{array}{c}\mathrm{E}_{\mathrm{a}} \\
\left(\mathrm{kJmol}^{-1}\right)\end{array}$} & $\begin{array}{c}\mathrm{Q}_{\mathrm{ads}} \\
\left(\mathrm{kJmol}^{-1}\right)\end{array}$ \\
\cline { 2 - 3 } & $30^{\circ} \mathrm{C}$ & $60^{\circ} \mathrm{C}$ & & \\
\hline Blank & & & 4.61 & \\
\hline 0.1 & 81.6 & 69.4 & 48.55 & -5.57 \\
\hline 0.15 & 82.2 & 73.2 & 54.54 & -4.36 \\
\hline 0.2 & 84.3 & 76.8 & 37.96 & -4.02 \\
\hline 0.25 & 86.7 & 80.4 & 84.17 & -3.85 \\
\hline 0.3 & 87.5 & 83.1 & 44.05 & -2.94 \\
\hline
\end{tabular}

Table 4. Calculated values of inhibition efficiency (I\%), apparent activation energy $\left(\mathrm{E}_{\mathrm{a}}\right)$ and heat of adsorption $\left(\mathrm{Q}_{\mathrm{ads}}\right)$ of Dialum guineense extract on AA3003 aluminium alloy in $0.25 \mathrm{M} \mathrm{NaOH}$ at different temperatures

\begin{tabular}{|c|c|c|c|c|}
\hline \multirow{2}{*}{$\begin{array}{c}\text { Extract Concen- } \\
\text { tration }\end{array}$} & \multicolumn{2}{|c|}{$\begin{array}{c}\text { Inhibition Efficiency } \\
(\mathrm{I} \%)\end{array}$} & \multirow{2}{*}{$\begin{array}{c}\mathrm{E}_{\mathrm{a}} \\
\left(\mathrm{kJmol}^{-1}\right)\end{array}$} & $\begin{array}{c}\mathrm{Q}_{\mathrm{ads}} \\
\left(\mathrm{kJmol}^{-1}\right)\end{array}$ \\
\cline { 2 - 3 } & $30^{\circ} \mathrm{C}$ & $60^{\circ} \mathrm{C}$ & & \\
\hline Blank & & & 4.61 & \\
\hline 0.1 & 82.7 & 75.2 & 17.97 & -3.78 \\
\hline 0.15 & 83.5 & 77.6 & 22.27 & -3.15 \\
\hline 0.2 & 83.7 & 77.9 & 6.41 & -3.13 \\
\hline 0.25 & 83.7 & 80 & 3.76 & -2.08 \\
\hline 0.3 & 87.5 & 82.4 & 45.39 & -3.34 \\
\hline
\end{tabular}

\subsection{Weight Losses and Corrosion Rates}

The weight loss of the aluminium alloy in $0.25 \mathrm{M} \mathrm{NaOH}$ with and without the various concentrations of plant extracts was determined after 4 hours of immersion at $30^{\circ} \mathrm{C}$. The corrosion rate was evaluated using Equation 1

$$
\rho=\frac{\mathrm{k} \Delta \mathrm{W}}{\mathrm{ADt}}
$$

Where $\Delta \mathrm{W}$ is weight loss, $D$ is the density of the metal, A is the cross sectional area of the metal and $t$ is the time of exposure in year. The corrosion rate is measured in $\mathrm{mm} / \mathrm{yr}$.
Equation 2 determines the inhibition efficiency ( I\% ) where $\rho_{\text {blank }}$ and $\rho_{\text {inh }}$ are the corrosion rates of aluminium alloy (AA3003) without and with the inhibitor, respectively. Values of the inhibition efficiency obtained are shown in figure 2 .

$$
\mathrm{I} \%=\left(1-\frac{\rho_{\text {inh }}}{\rho_{\text {blank }}}\right) \times 100
$$

Corrosion rate values of the alloy decrease when the inhibitor concentration increases. The inhibition efficiency increases with increasing inhibitor concentration, reaching optimum value of about $87.5 \%$ at $0.3 \mathrm{~g} / \mathrm{L}$ concentration of Euphorbia hirta and Dialum guineense extracts as shown in Figure 2.

\subsection{Inhibition Efficiency and Adsorption Considerations}

The characterization of the corrosion rate of aluminium alloy in the different inhibitor/ corrodent solutions was carried out by an assessment of inhibition efficiency using equation 2 above. In accounting for the observed protective effect, it should be noted that the extracts comprise mixture of organic and resinous matter (Table 5) some of which have good corrosion inhibiting abilities. The complex chemical compositions make it rather difficult to assign the inhibiting action to a particular constituent or group of constituents. Nevertheless, the net adsorption of the extract organic matter on the metal surface creates a barrier to charge and mass transfer, thus protecting the alloy surface from corrodent attack. The degree of protection varies for different extracts, with notable sensitivity to the inhibitor concentration. From Table 5, we observed some similarities in the phytochemical components of the extracts, particularly tannins, alkaloids, and essential oil. The inhibitive properties of tannins has been attributed to the reaction of the polyphenolic fraction of the tannins moieties, which ensures effective protection of the metal surfaces. The triterpeniod and other constituents also posses functional groups which are capable of chelating with aluminium ions and thus facilitate strong coordination on the alloy surface[15]. Having ascertained the effectiveness of these plant materials in the present study, subsequent studies to enable precise interpretation of the nature and composition of the absorbed inhibitor layer will be achieved from in-depth research of the corrosion morphology and characterization of the active materials in the absorbed layer is envisaged.

Table 5. Major constituents of the studied plants

\begin{tabular}{|c|c|}
\hline Plant & Major constituents \\
\hline Euphorbia hirta & $\begin{array}{c}\text { Triterpenoids, alkaloids, tannins, gly- } \\
\text { cosides, sterols, essential oil, flavones, } \\
\text { phenols. }\end{array}$ \\
\hline Dialum guineense & $\begin{array}{c}\text { Saponins, tannins, alkaloids, flavonoids, } \\
\text { essential oil. }\end{array}$ \\
\hline
\end{tabular}

(Okwu et al, 2003, Wikipedia) 


\subsection{Langmuir Adsorption Isotherms}

Further elucidation of adsorption mechanism from the experimental data requires estimation of the adsorption modes of the inhibiting species (whether molecular or ionic). The predominant adsorption mode will be dependent on factors such as the extract composition, chemical changes to the extract and the nature of the surface charge on metal. A negative surface charge will favour the adsorption of cations whereas anion adsorption is favoured by a positive surface charge. The plot of the ratio of concentration to surface coverage $(C / \theta)$ against concentration $(C)$ displayed a straight line for tested inhibitor (Fig. 3.4). Table 1 shows the correlation coefficient of the Langmuir adsorption isotherm. The linear plot with high correlation coefficient (0.999) and slope of about unity (1.10) clearly reveals that the surface adsorption process of Euphorbia hirta and Dialum guineense on the aluminium alloy surface obey the Langmuir adsorption isotherm. Therefore, one can infer that physisorption occurred.

\subsection{Temkin Adsorption Isotherms}

Temkin adsorption isotherm assumes a uniform distribution of adsorption energy, which decreases with the increase of the value of surface coverage, $\theta$. The Temkin adsorption isotherm which favour chemisorption was investigated. Figures 5 and 6 above shows a straight line with a high correlation coefficient. The free energy of adsorption, $\Delta \mathrm{G}^{\circ}$ ads, of -48.86 and $-138.34 \mathrm{kJmol}-1$ were obtained for Euphorbia hirta and Dialum guineense extracts respectively. The values obtained agrees with literature survey which suggests chemisotprtion[16-19].

\subsection{Effect of Temperature}

Two main types of interaction often describe adsorption of organic inhibitors on a corroding system viz: chemical adsorption and physical adsorption. It has been suggested that physisorbed molecules are attached to the metal at the cathodes and essentially retard metal dissolution by stifling the cathodic reaction whereas chemisorbed molecules protect anodic areas and reduce the inherent reactivity of the metal at the sites where they are attached[15,20].

The apparent activation energies (Ea) for the corrosion process in absence and presence of inhibitor were evaluated from Arrhenius equation.

$$
\log \frac{\rho_{2}}{\rho_{1}}=\frac{E_{\mathrm{a}}}{2.303 \mathrm{R}}\left(\frac{1}{\mathrm{~T}_{1}}-\frac{1}{\mathrm{~T}_{2}}\right)
$$

whereas estimates of the heats of adsorption $\left(\mathrm{Q}_{\mathrm{ads}}\right)$ were obtained from the trend of surface coverage with temperature as follows[21]:

$$
Q_{a d s}=2.303 \mathrm{R}\left[\log \left(\frac{\theta_{2}}{1-\theta_{2}}\right)-\log \left(\frac{\theta_{1}}{1-\theta_{1}}\right)\right] \times \frac{\mathrm{T}_{1} \mathrm{~T}_{2}}{\mathrm{~T}_{2}-\mathrm{T}_{1}}
$$

$\rho_{1}$ and $\rho_{2}$ are the corrosion rates in temperatures $T_{1}$ and $T_{2}$, respectively while $\theta_{1}$ and $\theta_{2}$ are the degrees of surface coverage at temperature $T_{1}$ and $T_{2}$ and $R$ is the gas constant.

$$
K=\frac{1}{55.5} \exp \left(\frac{-\Delta \mathrm{G}_{\mathrm{ads}}^{\circ}}{\mathrm{RT}}\right)
$$

The standard free energy of adsorption, $\Delta \mathrm{G}^{\circ}$ ads, which can characterize the interaction of adsorption molecules and metal surface, was calculated by Equation 5. The negative values of $\Delta \mathrm{G}_{\text {ads }}^{\circ}$ ensure the spontaneity of adsorption process and stability of the adsorbed layer on the aluminium surface. Generally, the values of $\Delta \mathrm{G}^{\circ}$ ads around $-20 \mathrm{~kJ} / \mathrm{mol}$ or lower are consistent with physisorption, while those around $-40 \mathrm{~kJ} / \mathrm{mol}$ or higher involve chemisorptions[22,24]. The values of free energy, $\Delta \mathrm{G}^{\circ}$ ads, obtained from the Langmuir isotherm plot are $-20.45 \mathrm{kJmol}^{-1}$ and $-24.04 \mathrm{kJmol}^{-1}$ for $E u$ phorbia hirta and Dialum guineense respectively which is consistent with literature survey and therefore authenticates physical adsorption, and the values of free energy, $\Delta \mathrm{G}_{\text {ads }}^{\circ}$, obtained from the Temkin isotherm plot are $-48.86 \mathrm{kJmol}^{-1}$ and $-138.34 \mathrm{kJmol}^{-1}$ for Euphorbia hirta and Dialum guineense respectively which is consistent with literature survey and therefore authenticates chemisorption. This implies that the plant extracts functioned via mixed inhibition mechanism.

\section{Conclusions}

Adsorption characteristics of the plant extracts were approximated by the Langmuir and Temkin isotherms. The inhibition mechanism, estimated from the temperature dependence of inhibition efficiency as well as activation parameters show that the extract exhibited mixed inhibition mechanism. Therefore, the Langmuir and Temkin isotherms were obeyed which authenticates the physisorbed and chemisorbed adsorption mechanism.

\section{ACKNOWLEDGEMENTS}

Our profound gratitude goes to the Educational Trust Fund (ETF) for its financial support to the success of this article.

\section{REFERENCES}

[1] Saleh, R. M. and Shams El Din, A. M., 1972. Efficiency of organic acids and their anions in retarding the dissolution of aluminium., Corrosion Science, 12(9), 689-697

[2] Maayta, A. K., 2002, Organic Corrosion Inhibitors for Aluminum in Sodium Hydroxide., 3, 25

[3] Okafor, P. C., Ekpe, U. J., Ebenso, E. E., Umoren, E. M. and Leizou, K. E., 2005, Inhibition of mild steel corrosion in acidic medium by Allium sativum extracts, Bulletin of Electrochemistry, 21(8), 347-352

[4] Donnelly, B., Downie, T. C., Grzeskowiak, R., Hamburg, H. R. and Short, D., 1978, The effect of electronic delocalization in organic groups $\mathrm{R}$ in substituted thiocarbamoyl R CS $\mathrm{NH} 2$ and related compounds on inhibition efficiency., Cor- 
rosion Science, 18(2), 109-116

[5] Tadros, A. B. and Abd-el-Nabey, B. A., 1988, Inhibition of the acid corrosion of steel by 4-amino-3- hydrazino-5-thio-1,2,4-triazoles Journal of Electroanalytical Chemistry and Interfacial Electrochemistry, 246(2), 433-439

[6] Subramanyam, N. C., Sheshadri, B. S. and Mayanna, S. M.,1993, Corrosion Science, 34(4), 563-571.

[7] Fouda, A. S., Moussa, M. N., Taha, F. I., Elneanaa, A. I., 1986, The role of some thiosemicarbazide derivatives in the corrosion inhibition of aluminium in hydrochloric acid, Corrosion Science, 26(9), 719-726

[8] Kliskic, M., Radoservic, J., Gudic, S. and Katalinic, V. , 2000, Aqueous extract of Rosmarinus officinalis L. as inhibitor of Al-Mg alloy corrosion in chloride solution, Journal of Applied Electrochemistry, 30(7), 823-830

[9] Sankarapapavinasam, S., Pushpanaden, F. and Ahmed, M. F., 1991, Tosyl-hydrazine, 4-nitrobenzoyl- hydrazine and terephthalyl- hydrazine as inhibitors for the corrosion of copper and aluminium in sulphiric acid. 21(7), 625-631

[10] Scholl, H., Jimenez, M. M. D., 1992, The application of 1hydroxyimidazole-3-N-oxides as aluminium corrosion inhibitors in alkaline solutions, Corrosion Science, 33(12), 1967-1978

[11] Khamis, E., and Atea,M., 1994, Inhibition of Acidic Corrosion of Aluminum by Triazoline Derivatives. Corrosion, 50, 106

[12] Oguzie, E. E., 2006, Studies on the inhibitive effect of Occimum viridis extract on the acid corrosion of mild steel. Materials Chemistry and Physics, 99, (2-3), 441-446

[13] Oguzie, E.E., 2005, Inhibition of acid corrosion of mild steel by Telfaria occidentalis, 34(6), $321-326$

[14] Oguzie, E.E., 2006, Adsorption and corrosion inhibitive properties of Azadirachta indica in acid solutions, 35(6), 334 340

[15] Oguzie, E. E., 2008, Corrosion Inhibitive Effect and Adsorp- tion Behaviour of Hibiscus Sabdariffa Extract on Mild Steel in Acidic Media., Port. Electrochim. Acta, 26(3), 303-314

[16] Umoren, S. A., Obot, I. B., Ebenso, E. E., and Okafor, P., 2008, Eco-friendly Inhibitors from Naturally Occurring Exudate Gums for Aluminium Corrosion Inhibition in Acidic Medium, Port. Electrochim. Acta, 26(3), 267-282

[17] Ebenso, E. E., Eddy, N. O. and Odiongenyi, A. O., 2009, Corrosion Inhibition and Adsorption Properties of Methocarbamol on Mild Steel in Acidic Medium, Port. Electrochim. Acta, 27(1), 13-22

[18] Obot, I. B., Obi-Egbedi, N. O., Umoren, S. A., and Ebenso, E. E., 2010, Synergistic and antagonistic effects of anions and ipomoea invulcrata as green corrosion inhibitor for aluminium dissolution in acidic medium, International Journal of Electrochemical Science, 5(7), 994-1007

[19] Nnanna, L. A., Onwuagba, B. N., Mejeha, I. M. and Okeoma, K. B.,2010, Inhibition effects of some plant extracts on the acid corrosion of aluminium alloy, 4, 011 - 016

[20] Ahlberg, E. and Friel, M., 1989, The cathodic polarization of iron in acidic acetonitrile-water solutions, Electrochimica Acta, 34(6), 771-780

[21] Bhajiwala, H M. and Vashi, R T., 2002, Ethanolamine, diethanolamine and triethanolamine as corrosion inhibitors for zinc in binary acid mixture $(\mathrm{HNO} 3+\mathrm{H} 3 \mathrm{PO} 4)$, Bulletin of Electrochemistry, 17(10), $441-448$

[22] Ebenso, E. E., 2003, Effect of halide ions on the corrosion inhibition of mild steel in $\mathrm{H} 2 \mathrm{SO} 4$ using methyl red - Part 1, Bulletin of Electrochemistry, 19(5), 209 - 216

[23] Oguzie, E.E., 2004, Influence of halide ions on the inhibitive effect of congo red dye on the corrosion of mild steel in sulphuric acid solution, Materials Chemistry and Physics, 87(1), 212-217

[24] Popova, A., Sokolova, E., Raicheva, S. and Christov, M., 2003, AC and DC study of the temperature effect on mild steel corrosion in acid media in the presence of benzimidazole derivatives, Corrosion Science, 45(1), 33-58 